\title{
Origen de clase, diploma educativo y expectativas laborales de los técnicos superiores en la provincia de Córdoba, Argentina
}

\author{
Eduardo Rodríguez Rocha* | Pablo Sebastián Gómez*** \\ MAURICIO AURELI****
}

El objetivo del artículo consiste en explorar la asociación entre origen de

Palabras clave

clase ocupacional y diploma educativo de la población estudiantil que ha optado por instruirse en carreras técnico-superiores de gestión estatal en la provincia de Córdoba para el año 2018. Para ello se hace uso de la primera fase de la Encuesta de Transición al Primer Empleo. Aplicamos la técnica de análisis de correspondencias múltiples y analizamos simultáneamente cómo se asocian diversos aspectos individuales, institucionales y sociales durante este proceso de formación técnico-profesional. Los resultados sugieren fuertes asociaciones entre los orígenes ocupacionales y determinados diplomas técnicos. Asimismo, cuando consideramos conjuntamente el origen de clase ocupacional con variables como el género y las expectativas laborales, la intensidad de las asociaciones persiste, aunque las direcciones varían según el sexo de la población bajo estudio.

The main goal of this article is to explore the link between occupational class origin and educational degree within the student population enrolled at technical colleges in state management careers in the Province of Córdoba (for the year 2018). In order to do this, we relied on the first phase of the First Job Transition Survey, applying the multiple correspondence analysis technique while simultaneously analyzing the interrelation among several individual, institutional, and social aspects at play during this technical-professional training process. The results suggest that there is a strong relation between occupational origins and certain technical studies degrees. Furthermore, when we jointly consider occupational class origins with variables such as gender and job expectations, the intensity of the interrelation persists, although the directions vary according to the sex of the population under study.

\author{
Educación técnica \\ Empleo \\ Origen de clase \\ Género
}

Expectativas laborales

\section{Keywords \\ Technical education \\ Employment \\ Class origin \\ Gender}

Job expectations

Recepción: 6 de marzo de 2020 | Aceptación: 12 de enero de 2021

DOI: https://doi.org/10.22201/iisue.24486167e.2021.174.59786

* Investigador asistente en el Consejo Nacional de Investigaciones Científicas y Técnicas de Argentina (CONICET) con sede en la Universidad Provincial de Córdoba (Argentina). Doctor en Sociología. Líneas de investigación: sociología de las migraciones; estratificación y desigualdad socioeducativa. Publicaciones recientes: (2019), "Percepciones de bienestar de migrantes sikh en Córdoba”, Revista Mexicana de Sociología, vol. 81, núm. 2, pp. 361-388; (2019), "La transición al primer empleo de los egresados técnicos superiores en la provincia de Córdoba", Revista Estudios Demográficos y Urbanos del CEDUA, vol. 34, núm. 2 (101),pp. 427-442. CE: edrodrocha@gmail.com

** Investigador asistente en el Consejo Nacional de Investigaciones Científicas y Técnicas de Argentina (CONICET), con sede en el Centro de Investigaciones y Estudios sobre Cultura y Sociedad (CIECS). Doctor en Demografía. Líneas de investigación: demografía social; migraciones internacionales; estadísticas social y multivariada; teorías del sur/interseccionales. Publicaciones recientes: (2021, en coautoría con M. Iglesias), "Incorporación laboral de migrantes sur-sur y sus hijos e hijas en Argentina: intersecciones de género, generaciones y trabajo”, Revista Brasileira de Estudios de População, Brasil (en prensa); (2021, en coautoría con M. Iglesias), "Investigar la incorporación de hijos de migrantes a través de Respondent Driven Sampling (RDS)”, Revista Estudios Sociológicos, vol. 39, núm. 117, pp.773-792.CE: pablosgomezpsg@gmail.com

*** Estudiante avanzado de la carrera de Ciencias de la Educación de la Universidad Nacional de Córdoba (Argentina). 


\section{INTRODUCCIÓN}

Dentro del campo latinoamericano de los estudios sobre estratificación y desigualdad social, el debate en torno a la articulación entre educación técnica y empleo ha generado relevantes investigaciones que abonan a la comprensión de las políticas institucionales que regulan las conexiones entre educación para el trabajo y mundo del trabajo. En términos generales, dichas investigaciones han discutido largamente el papel que cumple la escuela secundaria técnica, así como la educación universitaria tecnológica, en la trasmisión de concepciones y propuestas curriculares sobre el trabajo (Gallart, 2003; Fernández et al., 2018; De Moura y Bernasconi, 2005; Miranda, 2015; Ruiz, 2009; Hualde, 2003; Jacinto, 2013a, 2013b; Villa Lever, 2003; Murakami y Blom, 2008; García de Fanelli, 2013; CINTERFOR, 2006; Flores Crespo, 2005), empero, menos se ha investigado el rol de la educación postsecundaria no universitaria en la inserción ocupacional de sus egresados

Respecto al caso argentino, los trabajos que abordan los programas de educación técnicaempleo se han centrado fundamentalmente en el nivel medio; sin embargo, a partir de la promulgación de la Ley Nacional de Educación Técnica Profesional (26.058) del año 2006, la formación postsecundaria no universitaria ha cobrado mayor relevancia en los estudios académicos, tanto en la modalidad profesional como en la técnica (Jacinto, 2010, 2015; Sigal y Dávila, 2005). ${ }^{1}$ Específicamente la educación técnica superior (en adelante ETS), adquiere un interés especial, pues ésta constituye una instancia crucial en la formación de la fuerza de trabajo que busca insertarse laboralmente en los entramados productivos sectoriales de las diversas regiones del país. Desde su origen hasta nuestros días, la ETS en Argentina
- similar a otros contextos de la región- se ha concebido como un mecanismo para la rápida vinculación al trabajo de los sectores populares (Jacinto, 2015). Y si bien esta modalidad educativa fue pensada como un canal de promoción social de la clase trabajadora, también es necesario resaltar que debido a la inestabilidad del sistema político-democrático argentino, así como a los cambios en la organización del trabajo propios de los modelos de producción imperantes durante los regímenes de las últimas cinco décadas, la educación técnica careció por mucho tiempo de la jerarquía estatal-legal que habría permitido valorar los diplomas ofrecidos en su justa dimensión, por la sociedad y por los propios empleadores. ${ }^{2}$ Al respecto, durante la década de 1990, con la implementación de las reformas estructurales de corte neoliberal, la ETS devino una opción escolar de corta duración definida en función de las necesidades de las reconfiguraciones en la organización del trabajo. Concordamos con quienes señalan que esta modalidad de formación priorizó su papel como instrumento de mercado en lugar de posicionarse como un espacio de configuración de la identidad de los obreros especializados, así como de desarrollo de conocimientos y habilidades adecuadas a la demanda de empleo (Tedesco, 2012).

El subsistema de enseñanza superior en su modalidad técnica es pequeño en relación con otros subsistemas educativos; sin embargo, en años recientes ha crecido considerablemente. A ésta acuden aquellos jóvenes y adultos que ya han completado la educación obligatoria, o bien que cumplen con las condiciones establecidas en la Ley de Educación Superior, núm. 24.521. Es decir, se trata de individuos que han pasado por diversos procesos de selección educativa -el más importante es la finalización de la escuela secundaria técnica- y que

\footnotetext{
${ }^{1}$ En Argentina, el nivel educativo superior se conforma por la educación universitaria, la formación profesional docente y la educación técnica profesional (coloquialmente llamados terciarios). Ésta última es a la que nos abocamos. 2 Recién en la década de 1970, hasta la creación del Consejo Nacional de Educación Técnica (CONET), la educación técnica y la educación profesional se consolidaron en un mismo instrumento estatal. Sin embargo, esta modalidad educativa quedó marginada respecto al lugar que adquiría la educación general en el nivel medio (secundario general) y superior (universitario) (Jacinto, 2015).
} 
buscan incorporarse al mercado de trabajo en los sectores productivos de las diversas regiones del país. Precisamente, con la Ley 26.058, la matriculación en este subnivel educativo se ha incrementado interanualmente desde el año 2006 en 25 por ciento en todo el territorio nacional y ha alcanzado un stock promedio de 180 mil alumnos que acuden a institutos de gestión tanto pública como privada (Bottinelli y Sleiman, 2014; INET, 2016a, 2016b). Asimismo, como señalan investigaciones recientes, las lógicas pedagógicas de la formación técnicoprofesional se han acercado al discurso de los derechos socio-laborales por encima de las lógicas mercantilistas (Jacinto, 2015). Si bien se trata de un subsistema chico, para muchas pequeñas y medianas localidades del interior del territorio nacional los institutos educativos que albergan carreras técnicas superiores, ya sea de gestión estatal o privada, constituyen la única oportunidad de formación técnica postsecundaria para la población. Así, desde la perspectiva de la oferta educativa pública, la aplicación de la Ley 26.058 en localidades en donde no existían carreras universitarias u otras opciones de formación para el trabajo ha "asegurado mayores niveles de inclusión y adecuación en forma permanente a la oferta educativa y a las necesidades sociales, productivas y territoriales" (INET, 2016a: 1). Por ello, "inversión, mejoramiento de la calidad y fortalecimiento institucional se enmarcaron en una lógica de la formación técnica profesional como derecho" (Jacinto, 2015: 135).

De acuerdo con los postulados anteriores, consideramos que revisar la educación técnica superior constituye un hecho clave para comprender en qué medida dichos procesos educativos moldean las oportunidades reales de acceder al mundo laboral. Por ello, resulta pertinente preguntarse cómo se construye el vínculo entre la eventual fuerza laboral instruida en el nivel técnico-superior y los arreglos institucionales que configuran a los entramados productivos en el contexto de la provincia de Córdoba. En este trabajo intentamos dar un primer paso en ese sentido. Para ello, realizamos un estudio exploratorio de una investigación sociológica de más largo alcance, la cual pretende conocer los factores que moldean la calidad del empleo, así como la construcción social de la ocupación que realizan los técnicos superiores que venden su fuerza de trabajo en este contexto histórico (ver Rodríguez Rocha, 2019).

Para este artículo el objetivo es doble y más limitado: en primer lugar, analizamos la relación entre las regiones productivas en las que se emplazan las instituciones que albergan las carreras técnicas superiores en la provincia de Córdoba, la oferta de diplomas técnico-profesionales de egreso, la clase de origen ocupacional de esta población estudiantil y los activos culturales de su hogar hasta los 16 años de edad; y, en segundo lugar, analizamos las diferencias por género en las relaciones entre la clase de origen, activos culturales y las expectativas laborales. Con esto buscamos conocer qué ejes configuran el perfil técnico profesional de esta eventual fuerza de trabajo. Utilizamos un enfoque analítico relacional para estudiar el vínculo entre la clase ocupacional de origen y la posición social de los sujetos.

La limitación más importante del trabajo es que la posición social actual de los egresados de la ETS está dada por la obtención del diploma técnico de egreso; con esto sugerimos que los diplomas técnicos superiores constituyen un mecanismo de probable acceso a eventuales destinos ocupacionales. Así, el análisis del nexo entre clase ocupacional de origen y la titulación técnica se basará en el probable bienestar relativo de las personas respecto a sus orígenes familiares. En trabajos posteriores (cuando contemos con información de la calidad del empleo obtenido), podremos ensayar hipótesis acerca de movilidad, inmovilidad o desclasamiento ocupacional acerca de las condiciones de apertura o cierre social para esta eventual fuerza de trabajo. En otras palabras, podremos responder al interrogante de si aun en este periodo prolongado de baja 
creación de empleos, la ETS es un canal de ascenso social de las clases populares, o si, por el contrario, lo que se vislumbra es un cierre social de oportunidades vía la conformación de una clase obrera calificada.

El artículo se conforma por cuatro apartados y las conclusiones. En el primer apartado se traza brevemente el marco analítico; el segundo describe el contexto de estudio; el siguiente da cuenta de la técnica de análisis empleada; y el cuarto apartado presenta los resultados obtenidos. En el último se profundiza en los resultados del trabajo y se cierra con una síntesis general.

\section{ENFOQUE RELACIONAL PARA EL ESTUDIO DE LA FORMACIÓN DE LA CLASE TRABAJADORA CALIFICADA}

Nuestro enfoque busca interpretar el proceso de formación de una proporción de la clase trabajadora a través de vincular sus características de origen familiar y los diplomas de egreso, considerando otros aspectos de carácter individual/familiar (p. ej. características sociodemográficas, activos culturales y expectativas laborales), institucional (p. ej. características de los títulos educativos ofrecidos por los sistemas educativo) y social (p. ej. características de los entramados productivos a nivel regional). La propuesta que ensayamos en este artículo considera que las condiciones individuales/familiares o adscriptivas son factores primordiales en la constitución de oportunidades sociales vía la educación. Al mismo tiempo resaltamos el interjuego de aspectos institucionales y sociales como elementos significativos durante los procesos de formación técnico-profesional.

Para ello, desarrollamos una perspectiva relacional de clase que tiene sus fundamentos en las grandes corrientes sociológicas clásicas de la estratificación social. Esto es, asumimos que la condición de clase de origen (en este caso medida a través de la clase ocupacional del padre y la madre) ofrece probabilidades específicas para acceder a titulaciones técnicas. Es decir que la opción por la instrucción técnico-profesional no es ajena a las características de los recursos y capitales económicos y culturales heredados en el hogar de origen. En otras palabras, como se ha visto anteriormente para otros países latinoamericanos, y para el caso argentino en particular, la relación entre la situación de clase y los procesos de formación se enmarca en procesos de estratificación social fuertemente definidos por la trasmisión intergeneracional de ventajas/desventajas sociales (Dalle et al., 2019).

Dicho así, hipotéticamente la ETS puede ser concebida como una fuente de diferenciación social a la que los estudiantes y sus familias recurren para obtener las habilidades y los recursos simbólicos necesarios que les permitan superar - o al menos mantener- la posición social de origen. Si bien nos alejamos de las perspectivas credencialistas, somos conscientes de que los diplomas certifican la posesión de competencias lo que, en última instancia, influye en la condición social de los individuos, más todavía cuando se trata de los sectores populares, los cuales suelen acudir a las escuelas técnicas para acelerar o impulsar su ingreso al mercado de trabajo. Asimismo, a diferencia de enfoques como el reproduccionismo europeo o el marxismo clásico, nuestra perspectiva pondera positivamente la estructura institucional que enmarca a las carreras técnicas, vocacionales o de oficio, pues contamos con evidencia previa que señala que los sectores populares encuentran en estas modalidades educativas genuinas oportunidades de capacitación, instrucción y socialización escolar, a la vez que son fuentes significativas de capital social en la ulterior búsqueda de empleo (Ruiz, 2009; Flores Crespo, 2007; Arum y Shavit, 1995; Gamoran, 1987).

Para el caso argentino, los principales antecedentes de investigación que abordan el nexo entre carreras técnicas y empleo sustentan que hay dos condiciones determinantes sobre la inserción ocupacional: la carrera de egreso y la institución que emite el título ( $\mathrm{Pa}$ naia, 2017). Así, se ha señalado que el peso del 
origen familiar y el sexo del/de la estudiante pierden poder explicativo para describir los senderos que toman las trayectorias vitales de quienes han transitado por el nivel superior en sus modalidades técnica y tecnológica. Esto se replica en diversos contextos societales (Shavit y Mueller, 1998; Solís y Cortés, 2009). Sin embargo, eso no significa que las condiciones de origen no estructuren las trayectorias educativas (y eventualmente ocupacionales) de los sujetos; en cambio, lo que se sugiere es que, en la medida en que las trayectorias vitales de las personas avanzan (como es el caso de quienes han accedido al nivel superior), éstas devienen las más selectas socialmente, por lo que los dominios institucionales adquieren mayor peso en detrimento de los efectos individuales/familiares, los cuales reducen su influencia debido a las mediaciones producidas por las contingencias propias que experimentan las personas durante sus trayectorias vitales (Nelsen y Barley, 1997; Alba, 1981; Branch y Wilson, 2004). Con esto es posible argüir que el peso de los títulos y diplomas técnicos debe pensarse de manera contextualizada por regiones socio-productivas y matizarse entre diversas instrucciones técnico-profesionales.

Finalmente, nuestro enfoque considera que dos aspectos de carácter individual/familiar, como son las expectativas laborales y los climas culturales del hogar actual, pueden jugar un papel fundamental en la conformación de la eventual fuerza de trabajo inscrita en carreras técnicas superiores. En primer lugar, argüimos que las expectativas nos permiten echar luz sobre los escenarios a los cuales los sujetos que se encuentran en búsqueda de empleo esperan acceder. Al respecto, tenemos en cuenta trabajos que han señalado que tales expectativas pueden incrementar las oportunidades de acceder a los destinos educativos y laborales esperados (Solís et al., 2013).

Los estudios mencionados han encontrado que, si bien las expectativas de acceder a determinada posición social se asocian fuertemente con las propias aspiraciones configuradas en el seno del hogar de origen, dicha asociación no es perfecta (Solís et al., 2013). En tanto, se ha encontrado que cuando los estudiantes de menores recursos socioeconómicos cuentan con altas expectativas de acceder a una determinada posición social, sus trayectorias se ven impulsadas en relación con sus pares que no han desarrollado aspiraciones similares. También se afirma que las expectativas varían significativamente por sexo e institución escolar (Rodríguez Rocha, 2014). En segundo lugar, algunos trabajos sostienen que los climas culturales de los hogares varían a lo largo del curso de vida familiar, en especial cuando los/las hijos/as acceden a los niveles educativos superiores (Rodríguez Rocha, 2014). Si se considera que quienes acuden a la educación técnica superior son parte de los estudiantes socialmente más selectos dentro de los sectores populares, se esperaría que los activos culturales del hogar actual tengan algún rol en la conformación de los perfiles técnico-profesionales bajo estudio. El carácter exploratorio de variables como las expectativas y los activos culturales de los hogares de quienes están por egresar de las carreras técnicas podría profundizarse en posteriores trabajos abocados al tema.

\section{El CONTEXTO: CASO DE ESTUdio}

En Argentina, los estudios sociológicos que abordan el nexo entre educación técnica y empleo han tomado como contextos de análisis los grandes aglomerados urbanos a nivel nacional, con una especial atención en el Área Metropolitana de Buenos Aires. Asimismo, poco se ha profundizado en el peso específico del diploma técnico-profesional del nivel superior sobre las oportunidades de empleo, tanto en contextos mega-urbanos como en ciudades medianas y pequeñas. Por ello, analizar la relación entre los diplomas técnicos superiores y los sectores y ramas productivas a escala regional permitiría abonar al debate de las instituciones que configuran el empleo en la Argentina contemporánea. 
En tal sentido, Córdoba constituye un caso de estudio relevante por dos razones principales: en primer lugar, por su diversificada estructura productiva. Córdoba posee una tradición agroindustrial singular, en donde destaca su producción agrícola y ganadera. Sumadas a la caza y la silvicultura, estas cuatro actividades, en conjunto, conforman la segunda categoría en importancia del producto bruto general provincial (13.1 por ciento) (Bolsa de Comercio de Córdoba, 2017). ${ }^{3}$ La preponderancia del sector agropecuario ha impulsado diversas industrias alimenticias, así como una importante industria de maquinaria agrícola. ${ }^{4}$ Esta actividad económica se compone aproximadamente de 475 empresas, la mayoría de ellas incrustadas en encadenamientos productivos globales multinacionales, pero aglutina únicamente a 4 por ciento de los puestos de trabajo del sector privado provincial.

Córdoba destaca, además, por su tradición metalmecánica vinculada a las terminales automotrices ${ }^{5}$ y aeronáuticas, lo que ha generado un importante desarrollo sectorial, junto a otras industrias con cierto desarrollo productivo: plásticas, madereras, siderúrgicas, y recientemente del software. ${ }^{6}$ Por otro lado, el turismo constituye una industria de alta relevancia a nivel nacional: Córdoba es la segunda provincia, luego de Buenos Aires, con mayor oferta de infraestructura de alojamiento (posee 13.3 por ciento del total de establecimientos del país). El sector de hotelería y restaurantes representa 4.2 por ciento del total del empleo formal del sector privado en la provincia.

Desde una perspectiva regional, Córdoba se conforma por una geografía socio-productiva altamente heterogénea, con seis regiones claramente distinguibles: Centro, Sudoeste, Este, Traslasierra, Pampeana y Norte. Los departamentos con mayor nivel de actividad económica pertenecen a las regiones Centro (Capital y Colón), Sudoeste (Río Cuarto), Este (San Justo) y Pampeana (General San Martín y Unión), en las que se concentra 92 por ciento del producto consolidado provincial, básicamente en las actividades agroindustriales, manufactureras y en el heterogéneo sector del comercio y los servicios (Ministerio de Hacienda, 2018). Por su parte, los departamentos con menores niveles de actividad económica pertenecen a las regiones Norte y Traslasierra, en donde la actividad manufacturera es, excepto en Cruz del Eje, muy baja (Ministerio de Hacienda, 2018). En estas regiones las actividades principales se concentran en las ramas vinculadas a los servicios sociales y comunitarios, como el turismo y la administración pública.

La segunda razón de importancia para realizar el estudio en esta provincia es la variedad de la oferta educativa en el nivel técnico superior. En Córdoba acuden alrededor de 25 mil estudiantes ( 55 por ciento mujeres y 45 por ciento varones) a la ETS (INET, 2016a; 2016b). En lo que respecta al sistema de gestión pública provincial, que es el universo

\footnotetext{
3 Datos proporcionados por el informe "Economía argentina: habla el interior", del año 2017, elaborado por el Instituto de Investigaciones Económicas de la Bolsa de Comercio de Córdoba.

${ }^{4}$ Las externalidades generadas por esta actividad representaron 76 por ciento del total provincial en promedio en el periodo 1997-2006 y de 2006 al 2016 el 80 por ciento (Ministerio de Hacienda, 2018). De este total, 45 por ciento corresponde a manufacturas de origen agropecuario y 31 por ciento a productos primarios.

${ }^{5}$ Córdoba concentra 28 por ciento de la producción automotriz nacional y 25 por ciento de la producción autopartista, ambas actividades radicadas en la Capital, en tres firmas privadas. Sin embargo, también es elevado el porcentaje que aglutina la provincia (11 por ciento) respecto a la fabricación de carrocerías, remolques y semirremolques, la cual se encuentra dispersa en los departamentos de Río Segundo, Marcos Juárez, Gral. San Martin y San Justo, además de Capital. Si bien el empleo generado por el sector automotriz representa 19 por ciento del total sectorial a nivel nacional, desde el máximo nivel de empleo alcanzado en 2012 se observa una contracción de 2 mil 725 puestos de trabajo registrados (Ministerio de Hacienda, 2018).

${ }^{6}$ En el periodo 2005-2015 se incrementaron en 61 por ciento las empresas del sector de las actividades informáticas, mismas que ascendían a 343 en el último año de dicho decenio. En lo respectivo a empleo, en el segundo trimestre de 2017 los puestos de trabajo registrados en el sector fueron 6 mil 292, cifra 19 por ciento mayor que la del segundo semestre de 2016. Además, representa 6.5 por ciento del total de la actividad a nivel nacional (Ministerio de Hacienda, 2018).
} 
de análisis de esta investigación, se registran 38 institutos educativos que albergan 41 carreras técnicas, derivadas de las 25 orientaciones educativas del Catálogo Nacional de Títulos y Certificaciones, ${ }^{7}$ con una población base anual de 5 mil estudiantes en promedio (INET, 2016a; 2016b). En un contexto prolongado de baja creación de empleos, resulta relevante conocer ¿cómo se distribuyen los perfiles técnicos superiores en las regiones productivas de Córdoba? Asimismo, nos preguntamos ¿de dónde proviene socialmente dicha población y cuáles son los escenarios laborales a los que desean acceder una vez que egresen de la ETS?

\section{DATOS Y MÉTODO}

Para avanzar sobre esta propuesta de análisis se hará uso de la Encuesta en Panel de la Transición al Primer Empleo (EPTPE). Esta encuesta ha sido diseñada, aplicada y procesada por nuestro equipo de investigación con sede en el Centro de Investigaciones sobre Cultura y Sociedad (CIECS)-Consejo Nacional de Investigaciones Científicas y Técnicas (CONICET), con sede en la Universidad Nacional de Córdoba (ver Rodríguez Rocha, 2019). La encuesta es de corte longitudinal y permite captar, para el año 2018, la transición escuela-empleo de la fuerza de trabajo instruida en carreras técnicas-superiores impartidas en institutos técnicos superiores de gestión estatal localizados en las seis regiones socio-productivas de la provincia de Córdoba.

La encuesta cuenta con dos etapas de acopio de información: la primera consiste en una encuesta censal en la cual se recabó información de los estudiantes inscritos en el último año de formación en las carreras que se ofertaron en el año lectivo 2018; la segunda fase se encuentra en etapa de procesamiento de la información. ${ }^{8}$ En este trabajo nos centramos únicamente en la primera etapa de la encuesta.

Para esta primera fase se aplicaron de manera presencial 704 cuestionarios a estudiantes de tercer grado. La conformación de la muestra censal se dio de la siguiente manera: primeramente, se acordaron, las fechas en las que se aplicarían los cuestionarios, vía telefónica, con las autoridades respectivas de cada instituto/carrera técnica. La Inspección General de Educación Técnica Superior del Ministerio de Educación de la provincia de Córdoba, a su vez, coadyuvó en este proceso al invitar a cada instituto/carrera a colaborar con la investigación. Así, se les solicitó a los/las directores/as de las carreras que avisaran oportunamente a las cohortes de estudiantes de egreso a asistir en las fechas acordadas. En total se visitaron 18 instituciones educativas en las seis regiones socio-productivas de la Provincia de Córdoba en donde se instrumentaron 249 (36 por ciento) cuestionarios a estudiantes varones y 451 (64 por ciento) a estudiantes mujeres, lo cual arroja una tendencia similar a los datos provistos por el INET (2016). De esta población de estudio se desprende que contamos con información de estudiantes que cursaban 27 carreras técnicas en las diferentes regiones productivas de la provincia. Se puede hablar de muestra censal en tanto se visitó la totalidad de instituciones que para dicho año ofrecían carreras técnicas y se aplicaron cuestionarios a todos los estudiantes que estuvieron presentes al momento de la visita.

\footnotetext{
Las 25 distintas orientaciones socioproductivas son: 1) actividades artísticas y técnicas; 2) administración; 3) aeronáutica; 4) agropecuaria; 5) automotriz; 6) construcción; 7) cuero y calzado; 8) electromecánica; 9) electrónica; 10) energía; 11) energía eléctrica; 12) estética profesional; 13) hotelería y gastronomía; 14) industria de la alimentación; 15) industria de procesos; 16) industria gráfica y multimedial; 17) informática; 18) madera y mueble; 19) mecánica, metalmecánica y metalurgia; 20) minería e hidrocarburos; 21) naval; 22) salud; 23) seguridad, ambiente e higiene; 24) textil e indumentaria; 25) turismo.

${ }^{8}$ Esta etapa se instrumentó luego de 12 meses de egreso de los estudiantes encuestados, y ha apuntado al relevamiento de información para el estudio de la calidad del empleo. Los aspectos relacionados a la calidad ocupacional son: 1) el tipo de ocupación; 2) la protección legal: tipo de contratación (contrato por tiempo determinado, contrato por convenio colectivo de trabajo); 3) y la extensión de la jornada de trabajo: intensidad de la jornada laboral, diferenciando las de tiempo completo y las de tiempo parcial.
} 
Para las variables de origen de clase ocupacional se realizaron imputaciones para el padre/madre ausente cuando sólo se tenía información para uno. Así, se obtuvo una población de estudio $n=700$. Los casos no computados (4) se deben a que la persona encuestada no especificó la carrera técnica que estaba estudiando. Para analizar los datos en esta primera etapa utilizamos la técnica de análisis multivariado de correspondencias múltiples (ACM). Se optó por esta técnica como una estrategia metodológica que permite visualizar los patrones de correlaciones entre las variables seleccionadas. El objetivo principal de esta técnica es analizar datos categóricos que son transformados en tablas y presentar los resultados de manera gráfica.

El ACM es parte de un grupo de técnicas descriptivas (como el análisis de clúster, el análisis factorial o el análisis de componentes principales) que revela patrones y estructuras subyacentes en un conjunto de datos. El ACM puede sugerir dimensiones analíticas representadas en ejes que concentren la mayor cantidad de información posible. Así, en vez de inspeccionar múltiples tablas de manera secuencial detectamos patrones y asociaciones que permiten una interpretación visual del mapa de correspondencias. El análisis de los datos se realizó con el software R (R Core Team, 2019) con el paquete FactoMineR ${ }^{9}$ (Le et al., 2008). Para la visualización de los resultados se utilizaron los paquetes: factoextra (Kassambara, Mundt, 2017), ggplot2 (Wickham, 2009) y ggthemes (Arnold, 2018); para el análisis de los casos perdidos se utilizó el paquete missMDA (Josse y Husson, 2016).

Para desarrollar la perspectiva relacional de clase propuesta para este estudio exploratorio, hicimos uso del esquema de clases desarrollado por Erikson y Goldthorpe (1992a; 1992b), el cual se basa en la distinción de tres grandes clases sociales (de servicio, intermedias y trabajadoras) que, a su vez, contienen diez categorías ocupacionales en función del tipo de actividad realizada. ${ }^{10}$ Dicho esquema ha sido usado como base para versiones instrumentadas en distintos contextos latinoamericanos. Para versiones en el caso argentino reciente véase Dalle (2016). Así, se construyeron por separado clases de origen ocupacional tanto del padre como de la madre del/la estudiante encuestado/a:

- Clase de origen de la madre (6 categorías): clase de servicios y empleadores ((M)-serv-empleadores), clase intermedia asalariada ((M)-int-asalariada), pequeña burguesía ((M)-peq.bur), clase obrera no calificada ((M)-obrera-NC), clase obrera no calificada-polo marginal ((M)-O-NCpolo marginal), trabajo en el hogar no remunerado ((M)-hog-NR).

- Clase de origen del padre (5 categorías): clase de servicios y empleadores ((P)serv-empleadores), clase intermedia asalariada ((P)-int-asalariada), pequeña burguesía ((P)-peq.bur), clase obrera no calificada ((P)-obrera-NC), clase obrera no calificada-polo marginal ((P)-O-NC-polo marginal).

Las otras variables individuales/familiares construidas para este estudio son:

- Sexo (2 categorías): mujer, varón.

- Expectativa laboral (3 categorías): desearía trabajar por cuenta propia después de egresar de la carrera técnica (cuenta propia); desearía trabajar en la misma empresa que iniciaría mi carrera laboral (misma empresa); desearía trabajar en otro lugar al que iniciaría mi carrera laboral (otro lugar).

\footnotetext{
9 Se analizaron los casos perdidos en los datos. En nuestros datos se imputaron los datos perdidos mediante el paquete missMDA (Josse y Husson, 2016), sin embargo, no hubo cambios significativos en los resultados, por lo que se eliminaron los pocos casos perdidos encontrados.

10 Ver la Tabla 3 en el anexo.
} 
- Activos culturales, fundamentalmente recursos culturales (3 niveles) (índice de activos culturales, IAC): 1 (IAC bajo), 2 (IAC medio), 3 (IAC alto). Se construyó un índice compuesto de los siguientes diez indicadores: a) tiene mesa o escritorio utilizado para estudiar; b) computadora para utilizar en trabajos escolares; c) lugar tranquilo para estudiar; d) enciclopedias o diccionarios; e) libros de otros temas que no sean enciclopedias o diccionarios; f) acceso a Internet; g) recursos para salir a divertirse los fines de semana; h) automóvil; i) teléfono; j) televisión por cable (las variables son dicotómicas: 1 si tiene el bien, 0 si no lo tiene). El índice fue construido mediante la técnica de análisis de componentes principales (ACP) y se crearon terciles. ${ }^{11}$

Las variables institucionales y sociales incluidas en el análisis son:

\footnotetext{
- Carrera técnica según rama de actividad (10 categorías): ${ }^{12}$ agroindustria (agroind), manufactura (manufact), construcción (construc), servicios de electricidad y energía (elect-ener), servicios de administración (admin), servicios logísticos y de redes (log-red), servicios sociales y de salud (soc-salud), turismo (turismo), servicios sociales y comunitarios (soccomun), servicios sociales a organizaciones (soc-org.).

- Región (5 categorías): Noreste (NE), ${ }^{13}$ Centro (C), Sur-oeste (SO), Traslasierra (TS), Pampeana (Pampa).
}

\section{Resultados}

La Tabla 1 resume la distribución por sexo de estudiantes que estudiaban diversas carreras técnicas para la provincia de Córdoba. Como se aprecia, es posible sostener que son las carreras vinculadas a ramas de actividad del sector terciario de la economía (servicios), las que se sitúan en el primer lugar de preferencia de quienes egresarán como técnicos superiores: "administración" (24.2 por ciento) y "salud" (22.1 por ciento). Si bien las carreras agrupadas en estas dos ramas de actividad difieren significativamente en los campos de acción profesional (p. ej. contabilidad y enfermería), comparten la característica de ser carreras no manuales tradicionales, en las que la interacción social es una condición necesaria de la actividad profesional. Asimismo, se trata de carreras que en los imaginarios sociales se ubican como de "rápida inserción laboral". En segundo lugar, las carreras vinculadas a ramas de actividad como Informática (11.8 por ciento) y Electrónica (4.5 por ciento) ocupan un lugar relevante en los procesos de formación profesional de la eventual fuerza de trabajo, lo que coincide con la preponderancia que tiene la industria del software en los últimos años en la provincia.

Por otro lado, exceptuando las carreras como seguridad e higiene, informática, industria de los procesos y agropecuaria, que poseen significativamente mayor proporción de población varonil, en el resto de las carreras técnicas predominan las estudiantes mujeres. Estos primeros resultados no sólo refuerzan la idea de que existen preferencias

11 Existe una extensa literatura en la utilización de diversas técnicas para la construcción de índices con variables dicotómicas, con el clásico de Filmer y Pritchett (2001) como referencia obligada. Una aplicación con el lenguaje R, los problemas metodológicos, revisión de la literatura y utilización de análisis de componentes principales (ACP) puede encontrarse en Gómez (2014). Los estadísticos descriptivos se encuentran en la Tabla 3, en el Anexo.

12 Por razones de parsimonia analítica, decidimos fusionar la variable "carrera técnica" según la orientación educativa que propone el Catálogo Nacional de Títulos y Certificaciones. Así, denominamos a la variable que resume el título técnico-superior de egreso como "carrera según rama de actividad productiva". De tal manera contamos con información de 17 carreras según rama de actividad productiva.

${ }^{13}$ Fusionamos las variables regiones Norte y Este, por dos razones: por los pocos casos que la región Norte tenía y debido a una correspondencia similar en carreras vinculadas a carreras agroindustriales y alimenticias derivadas del campo. La región Norte presenta los más bajos niveles de actividad económica de la región, y únicamente pudimos encuestar a 10 estudiantes en la ciudad de Cruz del Eje. 
por determinadas orientaciones vocacionales según el sexo del estudiantado, sino que, con base en lo que sugieren los datos sobre productividad y demanda de trabajo provincial que hemos destacado más arriba, las carreras técnicas por las que optan los varones son aquéllas con mayor dinamismo económico y laboral. Así, es posible comenzar a ensayar una hipótesis de desigualdad de género relativa a la elección de los oficios o vocaciones profesionales para la fuerza de trabajo calificada en Córdoba.

Tabla 1. Distribución por sexo según carrera técnica de la población de estudio Carreras de gestión estatal en la provincia de Córdoba, 2018

\begin{tabular}{|c|c|c|c|}
\hline Carrera & Varón & Mujer & Total \\
\hline Actividades artísticas & 3 & 13 & 16 \\
\hline$\%$ & 1.2 & 2.88 & 2.29 \\
\hline Administración & 47 & 124 & 171 \\
\hline$\%$ & 18.88 & 27.49 & 24.43 \\
\hline Aeronáutica & 0 & 5 & 5 \\
\hline$\%$ & 0 & 1.11 & 0.71 \\
\hline Agropecuario & 13 & 8 & 21 \\
\hline$\%$ & 5.22 & 1.77 & 3 \\
\hline Construcción & 4 & 25 & 29 \\
\hline$\%$ & 1.61 & 5.54 & 4.14 \\
\hline Electrónica & 6 & 29 & 35 \\
\hline$\%$ & 2.41 & 5.76 & 4.57 \\
\hline Energía & 1 & 1 & 2 \\
\hline$\%$ & 0.4 & 0.22 & 0.29 \\
\hline Industria de alimentos & 17 & 25 & 42 \\
\hline$\%$ & 6.83 & 5.54 & 6 \\
\hline Industria de los procesos & 18 & 12 & 30 \\
\hline$\%$ & 7.23 & 2.44 & 4.14 \\
\hline Informática & 53 & 30 & 83 \\
\hline$\%$ & 21.29 & 6.65 & 11.86 \\
\hline Mecánica metalmecánica & 0 & 3 & 3 \\
\hline$\%$ & 0 & 0.67 & 0.43 \\
\hline Salud & 35 & 120 & 155 \\
\hline$\%$ & 14.06 & 26.61 & 22.14 \\
\hline Seguridad e higiene & 29 & 17 & 46 \\
\hline$\%$ & 11.65 & 3.77 & 6.57 \\
\hline Turismo & 21 & 33 & 54 \\
\hline$\%$ & 8.43 & 7.32 & 7.71 \\
\hline Sociales & 1 & 7 & 8 \\
\hline$\%$ & 0.40 & 1.55 & 1.14 \\
\hline Total & 249 & 451 & 700 \\
\hline$\%$ & 100 & 100 & 100 \\
\hline
\end{tabular}

Fuente: elaboración propia con base en la ETPTE. 
Ahora bien, respecto a la distribución de la oferta de educación técnica-superior según región socio-productiva, en la Tabla 2 es posible apreciar que las regiones Sudoeste y Traslasierra poseen la menor diversidad de diplomas técnicos disponibles. Resulta llamativo que la oferta educativa en el nivel técnico superior para la región Sudoeste, en donde se ubica la ciudad de Río Cuarto (la segunda ciudad en importancia económica y poblacional de la provincia), sea, por un lado, tan limitada y, por otro, tan sesgada hacia al sector terciario. En cambio, esta condición es entendible para la región Traslasierra, que posee una estructura productiva escasamente diversificada, centrada en la industria turística. Finalmente, las regiones Centro y Noreste son bastante similares en cuanto a la oferta de diplomas técnicos de egreso. Junto con la región Pampeana, los diplomas técnicos ofrecidos en estas tres regiones son variados y concentran la mayoría de la eventual fuerza de trabajo calificada que buscará insertarse laboralmente en la provincia de Córdoba y sus alrededores.

Tabla 2. Distribución de estudiantes por carrera técnica según regiones productivas de la provincia de Córdoba, 2018

\begin{tabular}{|c|c|c|c|c|c|c|}
\hline Carrera & Centro & Noreste & Sudoeste & Traslasierra & Pampeana & Total \\
\hline Actividades artísticas & 0 & 4 & 7 & 0 & 5 & 16 \\
\hline Administración & 23 & 67 & 36 & 7 & 38 & 171 \\
\hline Aeronáutica & 0 & 0 & 0 & 0 & 5 & 5 \\
\hline Agropecuario & 0 & 16 & 0 & 0 & 5 & 21 \\
\hline Construcción & 0 & 0 & 0 & 0 & 29 & 29 \\
\hline Electrónica & 0 & 0 & 0 & 0 & 32 & 35 \\
\hline Energía & 0 & 0 & 0 & 0 & 2 & 2 \\
\hline Industria de alimentos & 4 & 30 & 0 & 0 & 8 & 42 \\
\hline Industria de los procesos & 15 & 13 & 0 & 0 & 2 & 30 \\
\hline Informática & 43 & 16 & 4 & 3 & 17 & 83 \\
\hline Mecánica metalmecánica & 0 & 0 & 0 & 0 & 3 & 3 \\
\hline Salud & 53 & 0 & 4 & 32 & 66 & 155 \\
\hline Seguridad e higiene & 10 & 23 & 0 & 0 & 13 & 46 \\
\hline Turismo & 46 & 0 & 0 & 8 & 0 & 54 \\
\hline Sociales & 0 & 0 & 0 & 0 & 8 & 8 \\
\hline Total & 193 & 170 & 51 & 50 & 236 & 700 \\
\hline
\end{tabular}

Fuente: elaboración propia en base a la EPTPE, 2018.

\section{Análisis de correspondencias múltiples (ACM)}

Para analizar simultáneamente la asociación entre las dimensiones individuales/familiares (la clase de origen ocupacional de los estudiantes, los activos culturales del hogar actual), institucionales (la carrera según rama de actividad) y sociales (la región socio-productiva) presentamos los resultados del ACM. El Gráfico 1 permite observar:

1. Una fuerte asociación entre las regiones y las carreras técnicas (tanto en el eje horizontal como el vertical). La región Traslasierra y la Pampaeana se asocian con carreras vinculadas a la construc- 
ción y servicios sociales y de salud. Por su parte, la región Centro se asocia con un perfil vinculado a carreras según ramas de actividad de turismo, los servicios logísticos y de redes y la manufactura. La región Noreste (NE) se vincula a carreras de agroindustria, $y$ la región Suroeste a carreras de administración y servicios sociales y comunitarios. La visualización de estas relaciones constata que las regiones que cuentan con una oferta de diplomas altamente diversificada son el Centro y Noreste, y las regiones poco diversificadas, orientadas al sector servicios, se constituyen por el Sudoeste, Traslasierra y Pampeana. En otras palabras, es posible mapear una desigual oferta educativa mediante el vínculo entre la región socio-productiva y los diplomas existentes.

2. En segundo lugar, como era esperable, se observa una alta asociación y consistencia entre las clases sociales de origen del padre y de la madre, lo que sugiere que existe homogeneidad entre el origen social del padre y de la madre. Es decir, tanto el padre como la madre de los estudiantes tienen orígenes de clase similares: cuando el padre es de origen obrero no calificado del polo marginal, se correlaciona con el mismo origen social de la madre. Si observamos las clases sociales como la "pequeña burguesía" o las "clases sociales de servicios y empleadores" sucede lo mismo. En definitiva, en todas las clases sociales hay un patrón de alta correlación entre el origen social del padre y la madre. ${ }^{14}$

3. En tercer lugar, las clases sociales se vinculan a regiones socio-productivas y carreras especificas. Este resultado brinda elementos interesantes en el estudio de la conformación de un perfil de clase de la fuerza de trabajo para la provincia de Córdoba. Las clases sociales más altas se vinculan a la región Noreste, mientras que las carreras vinculadas a la agroindustria (tanto las alimenticias como las de maquinaria agrícola) son las más elegidas, a su vez, por los varones. Esto refuerza la idea de que, para quienes viven en pueblos y ciudades de la región Noreste, ser varón y provenir de un hogar pequeño burgués se asocia con la búsqueda de oportunidades laborales en el sector agroindustrial. Por su parte, las clases ocupacionales subalternas (O-NC y O-NC-PM) se asocian a la región de Traslasierra y a carreras vinculadas a servicios sociales de salud. En otras palabras, provenir de un hogar obrero no calificado, o en donde al menos alguno de los jefes del hogar hace "changas" (trabajo informal no regulado), se asocia a la elección por carreras como enfermería. Si bien este resultado era esperable, a partir del análisis realizado contamos con elementos suficientes para sostener que existe un mapa geográfico claramente estratificado por clase social y por perfil de la fuerza de trabajo instruida en escuelas técnicas superiores de gestión estatal.

4. Finalmente, y de manera específica, el índice de activos culturales (IAC) permite visualizar que los estudiantes procedentes de los hogares más calificados tienen mayor puntuación en el índice del hogar que habitaban al momento de la encuesta. Asimismo, es posible observar que éstos se vinculan a la región Noreste y a carreras de agroindustria y a servicios sociales

${ }^{14}$ El Gráfico 4 del anexo permite identificar la correlación entre las variables y las principales dimensiones del análisis de correspondencias múltiples. Las variables "índice de activos culturales" (IAC), "clase social de origen de la madre" y "clase social de origen del padre” se correlacionan con la dimensión 1. Por su parte, las variables "región” y "carrera técnica según rama de actividad" se correlacionan con las dimensiones 1 y 2. 
y organizaciones (eje horizontal valor 3 del índice). De igual manera, la clase social de origen de la madre vinculada a "clases de servicios y empleadores" y a la "pequeña burguesía", se asocian con una puntuación alta en el índice. En relación con la clase social de origen del padre se observa que quienes puntúan alto en el índice son la clase de servicios y empleadores, la clase intermedia asalariada y la pequeña burguesía. Por el contrario, quienes proceden de las clases ocupacionales subalternas tienen menor puntuación en el índice, y se vinculan a carreras relacionadas con construcción y servicios sociales de salud en las regiones Pampeana y Traslasierra. Por otro lado, en el cuadrante izquierdo se observan aquellos perfiles de carreras y clases ocupacionales de origen que tienen menor puntuación en relación al índice de activos culturales (valor 1). Las regiones Traslasierra y Pampeana, las carreras de construcción y servicios sociales y salud, así como las clases sociales de origen del padre y la madre vinculadas a la clase obrera no calificada polo marginal presentan una puntuación baja en los activos culturales con los que cuenta el hogar. Aquí es de destacar la alta correspondencia entre el origen de la madre y del padre en la clase obrera no calificada del polo marginal. Estos resultados coinciden con los hallazgos de investigación previos que señalan que la disposición de activos y climas culturales en el hogar dependen en gran medida de la clase ocupacional de los jefes de hogar.

Gráfico 1. Análisis de correspondencias múltiples. Toda la provincia

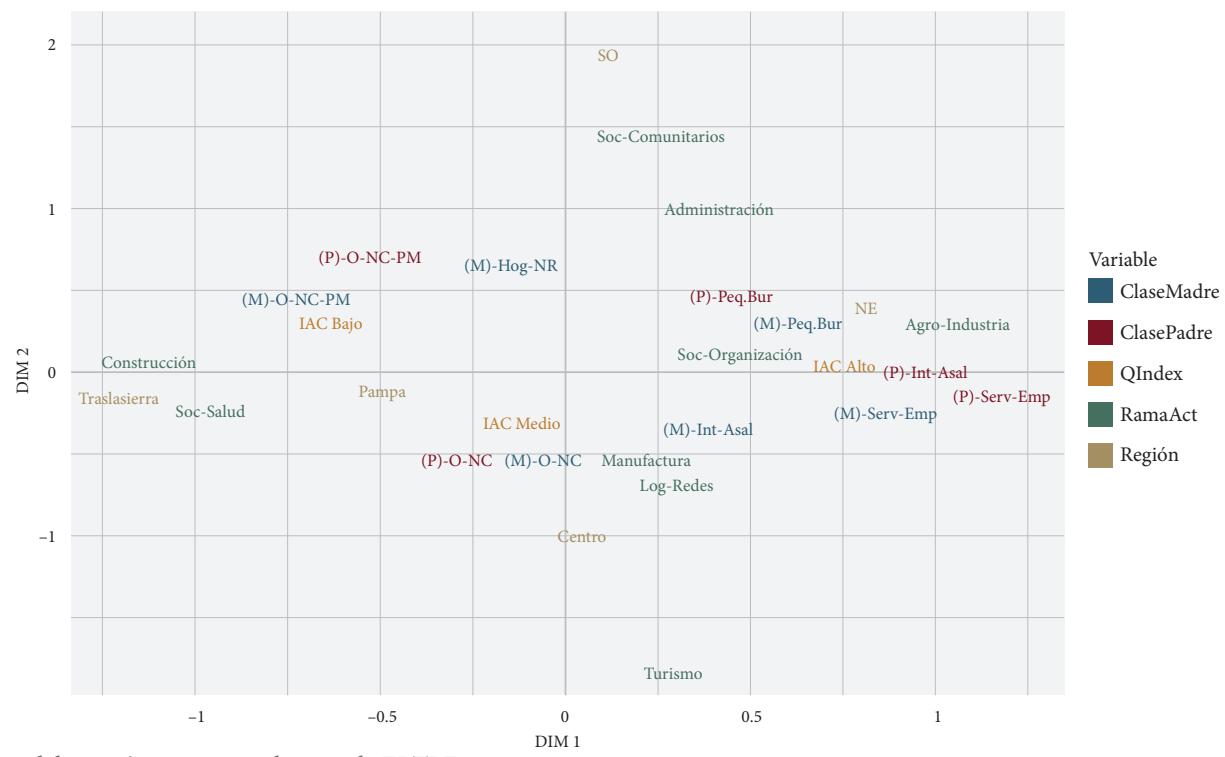

Fuente: elaboración propia con base en la EPTPE, 2018.

\section{Expectativas laborales y género}

Después de analizar la situación para el conjunto de los datos pondremos el foco en las diferencias por género de las expectativas laborales. Para los varones se observa la correlación de la variable clase del padre con la dimensión horizontal, la correlación del índice de activos culturales con ambas dimensiones y las expectativas laborales también con ambas dimensiones. Se observan los siguientes patrones (Gráfico 2): 
Gráfico 2. Análisis de correspondencias múltiples. Varones

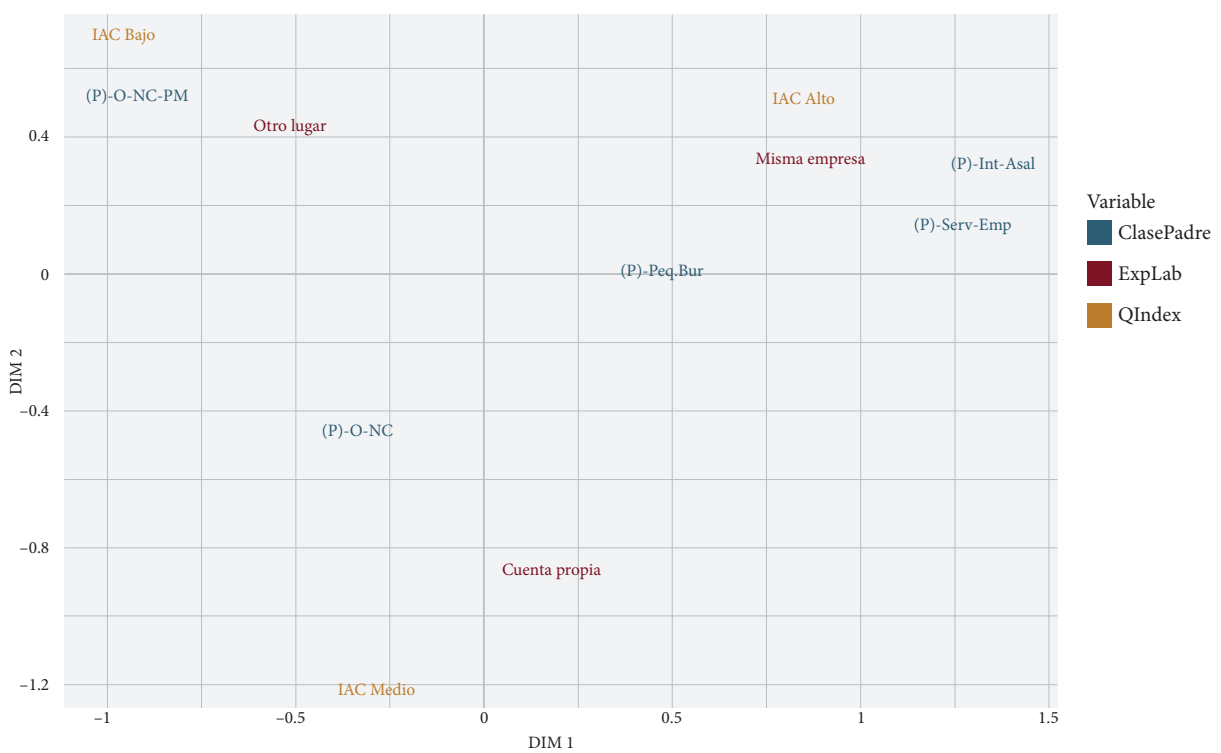

Fuente: elaboración propia con base en la EPTPE, 2018.

1. Alta correlación entre el índice de activos culturales bajo (IAC bajo), la clase social de origen perteneciente a obreros no calificados del polo marginal y expectativas de trabajar en otro lugar al que iniciaría la carrera laboral (cuadrante superior izquierdo).

2. Alta correlación entre las clases sociales de origen alto como la pequeña burguesía, servicios y empleadores e intermedias asalariadas con índice de activos culturales alto (IAC alto) y expectativas laborales de trabajar en la misma empresa en la que iniciaría la carrera laboral.

3. Alta correlación entre la clase social de origen de obreros no calificados, índice de activos culturales (IAC medio) y expectativas de trabajar por cuenta propia.

En el caso de las mujeres, hay una mayor asociación entre la clase social de origen del padre y los activos culturales (en ambos ejes), en tanto que las expectativas laborales se correlacionan con el eje vertical. Se observan los siguientes patrones (Gráfico 3):
1. Alta correlación entre el origen social perteneciente a obreros no calificados, índice de activos culturales medio (IAC medio) y expectativas laborales de trabajar en la misma empresa en la que iniciaría la carrera laboral.

2. Alta correlación entre el origen social perteneciente a obreros no calificados del polo marginal, índice de activos culturales medio (IAC medio) y expectativas laborales de trabajar en otro lugar al que iniciaría la carrera laboral.

3. Finalmente, se pueden observar relaciones entre el índice de activos culturales (IAC alto), orígenes sociales correspondientes a la pequeña burguesía, clase de servicios y empleadores e intermedios asalariados. Asimismo, existe correlación con las expectativas laborales de trabajar por cuenta propia (sin embargo, no es alta).

Estos resultados apuntan a que tanto para varones como para mujeres existe una fuerte asociación entre el origen social, los activos 
Gráfico 3. Análisis de correspondencias múltiples. Mujeres

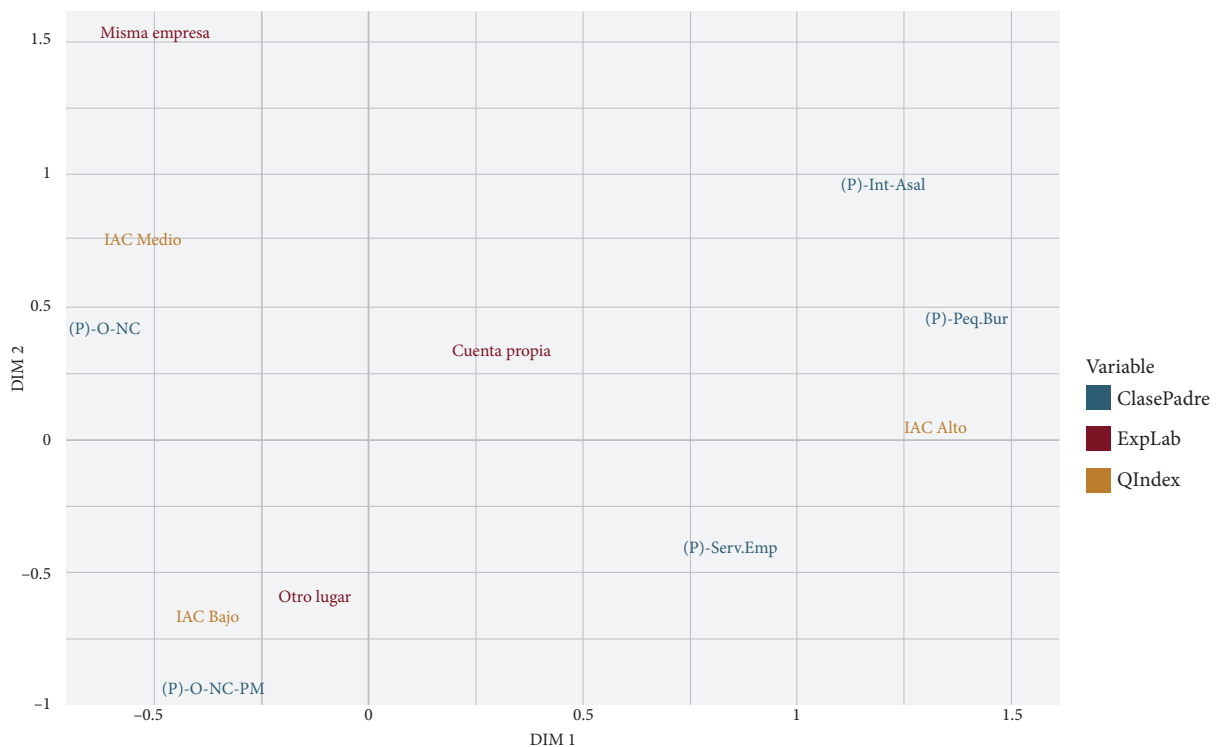

Fuente: elaboración propia con base en la EPTPE, 2018.

culturales y las expectativas laborales. Sin embargo, las direcciones son diferentes en relación con las expectativas laborales según el género:

1. En el caso de los varones, los que tienen menor puntuación en los activos culturales en su hogar actual, y que a su vez provienen de los hogares ocupacionales subalternos, tienen la proyección de trabajar en una empresa distinta a aquella en la que comenzarían su carrera laboral, y esto converge con lo que ocurre con las mujeres. Podríamos decir que se observa un patrón de eventual disposición a experimentar inestabilidad laboral hasta el momento de encontrar las condiciones de empleo que satisfagan sus expectativas. En otras palabras, estos eventuales técnicos superiores, de antemano, no esperan una inserción ideal en su tránsito al mundo laboral.

2. Los varones cuyo origen de clase y activos culturales son intermedios tienen expectativas de trabajar por cuenta propia, en tanto que las mujeres en la misma situación de clase y con activos culturales similares tienen expectativas de trabajar en la misma empresa donde iniciarían su carrera laboral.

3. Finalmente, los varones con orígenes de clase más altos y con mayor cantidad de activos culturales proyectan su trabajo en la misma empresa en tanto que las mujeres en una situación de clase similar están más cerca de proyectar su trabajo por cuenta propia.

Respecto a los dos puntos inmediatamente anteriores, tanto los varones como las mujeres mejor posicionadas en la estructura social cuentan con mayores esperanzas de encontrar estabilidad laboral al momento de su egreso de la escuela técnica que aquéllos/as procedentes de hogares subalternos y con menores niveles de capital cultural en su hogar actual. Estas diferencias en las expectativas según el género abren interrogantes para profundizar en trabajos futuros.

\section{CONCLUSIÓN Y DISCUSIÓN}

En este artículo exploramos las relaciones entre la clase de origen ocupacional de la población estudiantil que se instruye profesionalmente 
en carreras técnicas superiores de gestión estatal en la provincia de Córdoba, el diploma técnico de egreso y las regiones socio-productivas que contextualizan estos procesos de formación. El trabajo se basó en datos primarios relevados y construidos por nuestro propio equipo de investigación. De esta manera, desarrollamos una perspectiva que permitió captar diversas dimensiones individuales/familiares (origen de clase, sexo, disposiciones culturales del hogar y expectativas laborales), institucionales (distintas modalidades de diplomas técnicos) y sociales (características de las regiones productivas) de manera simultánea. La idea ha sido romper con la idea del peso determinante que se les suele dar a los factores adscriptivos sobre los procesos de logro educativo (y eventualmente ocupacional). Para ello, nuestra motivación se basó en investigaciones sociológicas previas que encontraron que cuando se analizan las asociaciones entre condiciones de origen de clase de las personas y su logro de estatus, existen elementos individuales, institucionales y sociales que potencialmente podrían explicar la heterogeneidad en la estructuración de los cursos de vida de las personas.

Para ello, desplegamos un enfoque relacional de clase que, sin ánimo de ser concluyente, nos permite dar cuenta, al mismo tiempo, de las fuertes asociaciones entre origen de clase y determinados títulos técnicos. Asimismo, pudimos explorar cómo otros aspectos, como las expectativas laborales, se asocian con estas dimensiones. En relación con los perfiles de las carreras se observa una fuerte asociación entre las regiones y los perfiles de las carreras técnicas, lo cual está en armonía con nuestro caso de estudio, caracterizado por la diversificada estructura productiva y la especificidad de la oferta educativa en el nivel técnico superior en cada región. Ahora bien ¿de dónde provienen socialmente y cuáles son los escenarios laborales de los técnicos superiores en Córdoba? El análisis indica que, por un lado, existe homogeneidad entre el origen social del padre y el origen social de la madre y, por el otro, una fuerte asociación entre las regiones socio-productivas y la composición de clase de éstas: la región de Traslasierra, asociada a clases obreras no calificadas, y la Noreste, a la pequeña burguesía, la clase de servicios y empleadores y la clase intermedia asalariada. Las clases sociales más altas se asocian con una mayor cantidad de activos culturales, y estas clases están radicadas en la región Noreste de la provincia, en tanto que los estudiantes procedentes de las clases subalternas y con menor cantidad de activos culturales se ubican en las regiones de Traslasierra y Pampeana. Es decir, las clases sociales se vinculan a regiones socioproductivas específicas, y esta vinculación se asocia también a los activos culturales con los que cuentan los individuos. En una palabra, los activos culturales de los hogares no se pueden diferenciar de la clase de origen y ambas condiciones pueden mapearse claramente en el territorio provincial.

Según la literatura revisada, el origen familiar y el género pierden poder explicativo para describir las trayectorias de quienes transitan por el nivel técnico superior. Sin embargo, en nuestros hallazgos, y en relación con las expectativas laborales, se sugiere la fuerte relevancia del género y los activos culturales como vectores que estructuran las proyecciones laborales. Debemos señalar que los datos analizados son el producto de un corte transversal y que aún no se analizan las trayectorias para ver en detalle el peso de los factores institucionales o familiares. En ese sentido, y en función de los resultados obtenidos, se encontró que las expectativas laborales están fuertemente asociadas al origen de clase, lo cual ha sido detallado en otros contextos. Es decir, tanto para varones como para mujeres existen altas asociaciones entre el origen social, los activos culturales y las expectativas laborales futuras; sin embargo, las direcciones son diferentes según el género, lo que sugiere la alta relevancia de este vector como estructurador de las proyecciones laborales. En primer lugar, los estudiantes procedentes de orígenes 
sociales más desaventajados desconfían de su primera experiencia laboral, y esperan encontrar su trabajo ideal en ulteriores empleos; en cambio, aquellos estudiantes procedentes de hogares de clases sociales mejor posicionadas confían que la primera experiencia laboral, por un lado, o el trabajo por cuenta propia, por otro, les generará la calidad laboral esperada. En otras palabras, la lección mertoniana de la acumulación de ventajas/desventajas asociadas al origen social parece cristalizarse de manera estratificada en las

\section{REFERENCIAS}

AlbA, Richard (1981), "Community Colleges and Tracking in Higher Education", Sociology of Education, vol. 54, núm. 4, pp. 223-237.

Arnold, Jeffrey (2018), Extra Themes, Scales and Geoms for 'ggplot2'. R package version 4.2.0, en: https://CRAN.R-project.org/package=gg themes (consulta: 26 de febrero de 2020).

Arum, Richard y Yossi Shavit (1995), "Secondary Vocational Education and the Transition from School to Work", Sociology of Education, vol. 68 , núm. 3, pp. 187-204.

Bolsa de Comercio de Córdoba (2017), Habla el interior. Economía argentina, Córdoba (Argentina), Instituto de Investigaciones Económicas.

Bottinelli, Leandro y Cecilia Sleiman (2014), “ ¿Uno de cada dos o dos de cada tres? Controversias sobre los niveles de egreso de la escuela secundaria”, El Observador. Dossier del Observatorio Educativo de la Universidad Pedagógica, vol. 1, núm. 2, en: http://observatorio. unipe.edu.ar/wp-content/uploads/2016/08/ Dossier-del-Observatorio-Educativo-deUNIPE-Educaci\%C3\%B3n-Secundaria.pdf (consulta: 26 de febrero de 2020).

Branch, Debra y George Wilson (2004), "Going Down: Race and downward occupational mobility for white-collar workers in the 1990s", Work and Occupations, vol. 31, núm. 3, pp. 283-322.

Dalle, Pablo (2016), Movilidad social desde las clases populares: un estudio sociológico en el Área Metropolitana de Buenos Aires 1960-2013, Buenos Aires, Universidad de Buenos AiresInstituto de Investigaciones Gino Germani.

Dalle, Pablo y Laura Stiberman (2017), "Clases populares en Argentina: cambios recientes en su composición ocupacional (1998-2015)", Encrucijadas. Revista Crítica de Ciencias Sociales, vol. 14, pp. 1-28. esperanzas laborales de los recién egresados de la ETS.

Esta investigación exploratoria tendrá su corolario una vez que recabemos la información respecto a la calidad de la inserción laboral de los técnicos superiores encuestados. Así contaremos con elementos suficientes para determinar efectivamente cómo los factores adscriptivos, institucionales o sociales moldean la inserción laboral de esta fuerza de trabajo altamente calificada en un periodo de baja creación de empleos.

Dalle, Pablo, Paula Boniolo y José Navarro Cendejas (2019), "Logro educativo y movilidad intergeneracional de clase en Argentina y México", en Màrius Domínguez i Amorós, Tabaré Fernández Aguerre e Ianina Tuñón (coords.), Viejos y nuevos clivajes de la desigualdad educativa en Iberoamérica, Buenos Aires, CLACSO, pp. 127-163.

De Moura Castro y Ana Bernasconi (2005), Los institutos técnicos superiores norteamericanos y América Latina: ¿clonación, inspiración o rechazo?, Washington, D.C., IADB.

ErIKson, Robert y John H. Goldthorpe (1992a), "The CASMIN Project and the American Dream", European Sociological Review, vol. 8, núm. 3, pp. 283-305.

ErIKson, Robert y John H. Goldthorpe (1992b), The Constant Flux: A study in class mobility in industrial societies, Oxford, Clarendon Press.

Fernández Aguerre Tabaré, Agustina Márquez Hill y Virginia Loranzo Holm (2018), "Educación media técnica y la inserción laboral entre los 16 y los 25 años en Uruguay. Un estudio con base a los microdatos del Panel PISA 2003-2012", Lavboratorio, vol. 18, núm. 28, pp. 114-142.

Filmer, Deon y Lant Pritchett (2001), "Estimating Wealth Effects without Expenditure Data-or Tears: An application to educational enrollments in states of India", Demography, vol. 38, núm. 1, pp. 115-132.

Flores Crespo, Pedro (2005), Educación superior y desarrollo humano: el caso de tres universidades tecnológicas, México, ANUIES, Biblioteca de la Educación Superior.

Flores Crespo, Pedro (2007), Educación superior y desarrollo humano, México, ANUIES/UIA, Biblioteca de la Educación Superior.

Gallart, María Antonia (2003), La formación para el trabajo en la Argentina: situación actual y perspectivas para el futuro, Santiago de Chile, CEPAL/GTZ. 
Gamoran, Adam (1987), "The Stratification of High School Learning Opportunities", Sociology of Education, vol. 3, núm. 60, pp. 135-155.

García de Fanelli, Ana (2013), “Training the 21st Century Knowledge Workers: Higher education and workforce development in Latin America”, en Jorge Balán (ed.), Latin American's New Knowledge Economy: Higher Education, government and international collaboration, Nueva York, Institute of International Education (IIE)/American Institute for Foreign Study (AIFS) Foundation, pp. 19-38.

Gobierno de Argentina-Ministerio de Hacienda (2018), Informe productivo provincial. Córdoba. Mayo 2018, Córdoba (Argentina), Secretaría de Política Económica.

Gómez, Pablo (2014), "Construcción de estratos socioeconómicos en Paraguay: aplicación con análisis de componentes principales", Revista Astrolabio, núm. 12, pp. 422-447.

Hualde Alfaro, Alfredo (2003), "Trayectorias laborales, aprendizaje y condiciones de empleo de técnicos: un análisis en Tijuana y Mexicali”, Revista de la Educación Superior, vol. 32, núm. 126, pp. 97-109.

INET (2016a), La educación técnico profesional en cifras 2016. Informe estadístico nacional, Buenos Aires, Presidencia de la Nación-Ministerio de Educación y Deportes.

INET (2016b), Nómina de instituciones de educación técnica profesional de nivel superior ingresadas a la base de datos del Registro Federal de Instituciones de Educación Técnica Profesional (RFIETP) al 31 de agosto de 2016, Buenos Aires, Presidencia de la Nación-Ministerio de Educación y Deportes.

Jacinto, Claudia (2010), "Veinte años de políticas de formación para el empleo de jóvenes vulnerables en América Latina”, en Claudia Jacinto (comp.), La construcción social de las trayectorias laborales de los jóvenes, Buenos Aires, Ides Teseo, pp. 119-148.

Jacinto, Claudia (ed.) (2013a), Incluir a los jóvenes. Retos para la educación terciaria técnica en América Latina, París, UNESCO-IIPE.

Jacinto, Claudia (2013b), "La educación post-secundaria técnica: contexto, interrogantes y aportes de la investigación", en Claudia Jacinto (ed.), Incluir a los jóvenes. Retos para la educación terciaria técnica en América Latina, París, UNESCO-IIPE, pp. 39-66.

JaCinto, Claudia (2015), "Nuevas lógicas en la formación profesional en Argentina. Redefiniendo lo educativo, lo laboral y lo social", Perfiles Educativos, vol. 120, núm. 148, pp. 120-137.

Josse Julie y Francois Husson (2016), "A Package for Handling Missing Values in Multivariate Data Analysis", Journal of Statistical Software, vol. 70, núm 1, pp. 1-31.
Kassambara, Alboukadel y Fabian Mundt (2017), Extract and Visualize the Results of Multivariate Data Analyses. $R$ package version 1.0.5, en: https://CRAN.R-project.org/package=facto extra (consulta: 26 de febrero de 2020).

Le Sebastien, Josse Julie y Francois Husson (2008), "FactoMineR: An R Package for Multivariate Analysis", Journal of Statistical Software, vol. 25, núm. 1, pp. 1-18.

Miranda, Ana (2015), Sociología de la educación y transición al mundo del trabajo. Juventud, justicia y protección social en la Argentina contemporánea, Buenos Aires, Teseo/ FLACSO.

Murakami, Yuki y Andreas Blom (2008), Accessibility and Affordability of Tertiary Education in Brazil, Colombia, Mexico and Peru within a Global Context, Policy Research Working Paper 4517, Washington, D.C., Banco Mundial.

OIT-CINTERFOR (2006), Calidad, pertinencia y equidad. Un enfoque integrado de la formación profesional, Montevideo, OIT-CINTERFOR.

Panaia, Marta (2017), De la formación al empleo. El desafío de la innovación, Buenos Aires, Miño y Dávila.

R Core Team (2019), R: A language and environment for statistical computing. $R$ Foundation for Statistical Computing, Viena, en: https:// www.R-project.org/ (consulta: 26 de febrero de 2020).

Rodríguez Rocha, Eduardo (2014), "El rol de las elecciones educativas en la transición a la educación media superior en la Ciudad de México", Revista Latinoamericana de Población, año 8, núm. 15, pp. 119-144.

RODRÍGuEz Rocha, Eduardo (2019), "La transición al primer empleo de los egresados técnicos superiores en la provincia de Córdoba”, Revista Estudios Demográficos y Urbanos del CEDUA, vol. 34, núm. 2 (101), pp. 427-442.

Ruiz, Estela (2009), "Los técnicos superiores universitarios. Diferenciación educativa, estratificación social y segmentación del trabajo", $R e$ vista Mexicana de Sociología, vol. 71, núm. 3, pp. 557-584.

Shavit, Yossi y Walter Mueller (eds.) (1998), From School to Work: A comparative study of educational qualifications and occupational destinations, Oxford, Clarendon.

Sigal Víctor, Mabel Dávila (2005), La educación superior no universitaria argentina, Buenos Aires, Siglo XXI.

Solís, Patricio y Fernando Cortés (2009), "La movilidad ocupacional en México: rasgos generales, matices regionales y diferencias por sexo", en Cecilia Rabell Romero (ed.), Tramas familiares en el México contemporáneo. Una perspectiva sociodemográfica, México, UNAM-Instituto de Investigaciones Sociales/ El Colegio de México, pp. 395-433. 
Solís, Patricio, Eduardo Rodríguez Rocha y Nicolás Brunet (2013), "Orígenes sociales, instituciones y decisiones educativas en la transición a la escuela media superior. El caso del Distrito Federal", Revista Mexicana de Investigación Educativa, vol. 18, núm. 59, pp. 1103-1136.

Tedesco, Juan Carlos (2012), Educación y justicia social en América Latina, Buenos Aires, FCE.

VIlla Lever, Lorenza (2003), "Las universidades tecnológicas: una nueva estrategia de las políticas de formación en México", en María Josefa Santos Corral (comp.), Perspectivas y desafíos de la educación, la ciencia y la tecnología, México, UNAM-Instituto de Investigaciones Sociales, pp. 81-138.

Wicкнам Hadley (2016), Elegant Graphics for Data Analysis, Nueva York, Springer-Verlag. 
La Tabla 3 reporta los scoring factors del análisis de componentes principales (primer componente) para las 10 variables, con media 0 y desviación estándar 1.62. Como todas las variables toman el valor de 0 o 1 , el peso tiene la siguiente interpretación: pasar de 0 a 1 cambia el índice de acuerdo con el valor del scoringfactor/desviación estándar.

Tabla 3. Variables utilizadas en la construcción del índice de activos culturales

\begin{tabular}{lcccc}
\hline \multicolumn{1}{c}{ Variables } & Scoringfactors & Media & D.E & $\begin{array}{c}\text { Scoring } \\
\text { factors/D.E }\end{array}$ \\
\hline Tiene mesa o escritorio para estudiar & 0.28 & 0.72 & 0.450 & 0.623 \\
\hline $\begin{array}{l}\text { Tiene computadora para utilizar en } \\
\text { trabajos escolares }\end{array}$ & 0.29 & 0.88 & 0.329 & 0.892 \\
\hline Tiene lugar tranquilo para estudiar & 0.32 & 0.61 & 0.488 & 0.661 \\
\hline Tiene enciclopedias o diccionarios & 0.39 & 0.52 & 0.500 & 0.774 \\
\hline $\begin{array}{l}\text { Tiene libros de otros temas (además } \\
\text { de enciclopedias) }\end{array}$ & 0.38 & 0.58 & 0.495 & 0.759 \\
\hline Tiene acceso a Internet & 0.26 & 0.90 & 0.302 & 0.857 \\
\hline Tiene recursos para salir a divertirse & 0.41 & 0.48 & 0.500 & 0.823 \\
\hline Tiene automóvil & 0.30 & 0.51 & 0.500 & 0.609 \\
\hline Tiene teléfono & 0.24 & 0.87 & 0.332 & 0.720 \\
\hline
\end{tabular}

Fuente: elaboración propia con base en la EPTPE, 2018.

Gráfico 4. Correlación entre las variables y las principales dimensiones del ACM

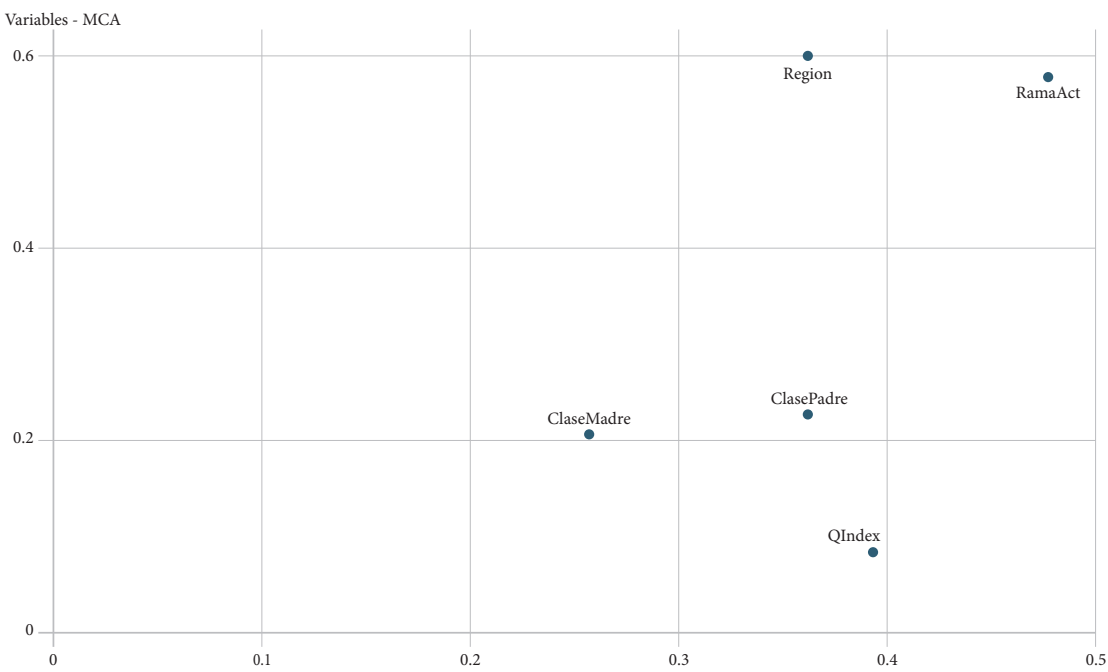

Fuente: elaboración propia con base en la EPTPE, 2018. 
Tabla 4. Categorías ocupacionales con base en el esquema CASMIN

\begin{tabular}{|c|c|c|}
\hline Relación de empleo & Ocupaciones incluidas & Cinco categorías \\
\hline Relación de servicio & $\begin{array}{l}\text { Profesionales y directivos de nivel alto; grandes } \\
\text { empleadores }\end{array}$ & Clase de servicios y empleadores \\
\hline $\begin{array}{l}\text { Relación de servicio } \\
\text { (modificada) }\end{array}$ & $\begin{array}{l}\text { Profesionales y directivos de nivel bajo; técnicos de } \\
\text { alto nivel }\end{array}$ & \\
\hline (No asalariados) & Pequeños empleadores & \\
\hline \multirow[t]{2}{*}{ Forma mixta } & Empleados no manuales de rutina, nivel alto & \multirow[t]{2}{*}{ Clase intermedia asalariada } \\
\hline & $\begin{array}{l}\text { Técnicos de bajo nivel, supervisores de nivel bajo de } \\
\text { trabajadores manuales }\end{array}$ & \\
\hline \multirow[t]{2}{*}{ (No asalariados) } & Trabajadores agropecuarios autónomos & \multirow[t]{2}{*}{ Pequeña burguesía } \\
\hline & $\begin{array}{l}\text { Pequeños empleadores y trabajadores autónomos } \\
\text { rurales }\end{array}$ & \\
\hline \multirow[t]{2}{*}{ Contrato de trabajo } & Empleados no manuales de rutina, nivel bajo & \multirow[t]{2}{*}{ Clase obrera no calificada } \\
\hline & Trabajadores manuales calificados & \\
\hline \multirow[t]{2}{*}{ Contrato de trabajo } & $\begin{array}{l}\text { Trabajadores manuales no calificados, no } \\
\text { agropecuarios }\end{array}$ & \multirow[t]{2}{*}{ Clase obrera no calificada } \\
\hline & Trabajadores manuales no calificados, agropecuarios & \\
\hline $\begin{array}{l}\text { Sin contrato de trabajo } \\
\text { (cuentapropistas) }\end{array}$ & "Changas", trabajo informal no regulado & Clase obrera no calificada \\
\hline
\end{tabular}

Fuente: elaboración propia adaptada del esquema original de Erikson y Goldthorpe (1992b). 